\title{
The Influence of Structural Dimensions on Judgement of Similarity/Dissimilarity Judgement When Categorizing Paintings: A Developmental Study Proposal
}

\section{John Hughley}

Introduction

Flavell (1963), Neisser (1976), Crozier and Chapman (1984) consider structures as largely determining the type of information a perceiver accepts, thus controlling the activity of looking. These structures are not fixed and one's response to the external world is in accordance with his or her existent cognitive structures. In addition, Chapman (1978), Lansing (1976), and Marschalek (1983) indicate that the cognitive structures influence perceptions and responses to objects of art, and since perception is a primary process of cognition, it assists in the make up of such higher order processes as problem solving, reasoning, and thinking.

Consequently, the proposed study concerns conceptual and perceptual development of children as it relates to art, specifically painting.

\section{Statement of the Problem}

The main purpose of this proposal is to investigate and evaluate the developmental influence of structural dimensions, subject matter and degree of realism, and their developmental influence on the categorization of paintings.

Several questions arise when investigating and evaluating the significance of this proposed study. What research evidence is there that structural dimensions influence the classification of paintings? What variables are characteristic to the influence of structural dimensions at different developmental stages? Is there a focus on specific dimensions? Answering such questions increases knowledge toward understanding responses to art.

\section{Significance of the Problem}

Classification, a cognitive concept, deals with relations between objects (logico-arithmetic operations) and relations within objects (spatial operations). In studies by Walk (1967; 1971) and Tighe (1968), differentiating the artistic styles of various artists is a conceptual task that reveals the ability to make classifications. 
The proposed study uses a match-to-match sample paradigm with the polar adjective combination similar-dissimilar to investigate the use of subject matter and degree of realism (parts \& wholes) by children to make similarity/dissimilarity judgements when categorizing paintings. Research by Hardiman and Zernich $(1977 ; 1982)$ suggests that the structural dimensions, subject matter and degree of realism are salient variables for all age groups in preference studies with painting stimuli, thereby significantly influencing responses to such stimuli. Consequently, subject matter and degree of realism were chosen as variables for this research project.

\section{Statement of Hypothesis}

In light of the purpose of the proposed study to investigate the influence of structural dimensions on similarity/dissimilarity judgement when categorizing paintings, three research questions were investigated.

1. Is degree of realism, a holistic variable, dominant in shaping similarity/dissimilarity judgement at each grade level when categorizing paintings?

2. Do young and older children categorize paintings on the basis of perceptual similarities and abstract criteria (part and whole relations)?

3. Do younger children initially categorize realistic paintings on the basis of subject matter (thematic schemes) which is more familiar and common to the child's functional relations and activities?

Answers to the three research questions are provided by determining if any statistically significant differences exist between grades. The following hypothesis has been formulated to make this determination.

There will be no significant differences at all grade levels.

\section{Methodology}

\section{Stimulus Materials}

The stimuli consist of 20 pairs of $2^{\prime \prime} \times 2^{\prime \prime} 35 \mathrm{~mm}$ slides of paintings with 4 slide pairs used for practice trails. There is one study slide for each slide pair. Slides were grouped and rated according to similarity/dissimilarity, of subject matter and realism on a scale from 1 (least similar) to 7 (most similar) by four graduate students in Art Education and Art History. When grouped the slides were placed in one of four categories: (a) similar subject matter/similar realism; (b) similar subject matter/dissimilar realism; (c) dissimilar subject matter/similar realism; (d) dissimilar subject matter/dissimilar realism. The graduate students also rated the degree of realism for the slides on a 7-point rating scale ranging from 1 (least realistic) to 7 (most realistic). Realism is defined as works that are accurate and natural 
representations of subject matter, including natural proportions, perspective, definition of detail (clarity), light and value and the use of local color. The subject matter categories include landscapes with people, landscapes without people, seascapes and interiors.

Design

The variables (similarity category \& degree of realism) were manipulated within grades $1,3,5$ and 7 . There are 4 slide pairs in each of the 4 similarity categories and an equal number of subjects are included in each cell of the study. A random presentation order was established for the presentation of slides.

\section{Subjects}

The sample consisted of 120 subjects from grades $1,3,5$ and 7 (ages 5-7, 7-9, 9-11 \& 11-13, respectively). An equal number of subjects were randomly selected from each grade level. The subjects were chosen from central Illinois schools. The researcher selected the subjects from each class and the subjects had no formal instruction in art. Their parents were generally well educated and professionally employed.

\section{Procedure}

A Kodak carrousel slide projector was used to project the slides for approximately 15 seconds. Following the exposure of the study slide there was a five second blank. Then the slide pair was shown in sequence and the subjects determined which slide of the pair is more like the study slide by circling yes, for similar, under the appropriate slide number on the answer sheet.

\section{Data Analysis}

Data analysis was accomplished by using analysis of variance (subject $x$ stimuli) for repeated measures design. A three-factor analysis of variance is performed for grade, similarity category and degree of realism. In addition, a two factor analysis of variance was performed for similarity category and degree of realism for each grade level. Analysis of contrast for the SAS catmod procedure was used to determine any significant differences among means.

\section{References}

Chapman, L. (1978). Approaches to art. New York: Harcourt, Brace Jovanovich.

Crozier, W. R. \& Chapman, A. J. (1984). The perception of art: The cognitive approach and its context. In W. R. Crozier and A. J. Chapman (eds.), 
Cognitive processes in the perception of art. North-Holland: Elsvier Science Publishers B.V., 3-23.

Flavell, J. H., (1963). The developmental psychology of Jean Piaget. New York: Van Nostrand Reignold.

Hardiman, G. W. \& Zernich, T. (1977). The influence of style and subject matter on the development of children's art preferences. Studies in Art Education, 19, (1), 29-35.

Hardiman, G. W. \& Zernich, T. (1982). The relative influence of parts and wholes in shaping preference responses to paintings. Studies in Art Education, 23, (3), 31-38.

Lansing, K. (1976). Art, artist and art education. Dubuque, lowa: Kendall/Hugh.

Marschalek, D. G. (1983). The influence of viewing time upon the recognition of color and subject matter placement in paintings for elementary and high school students. Studies in Art Education, 25, (1), 58-65.

Neisser, U. (1976). Cognition and reality. San Francisco, California: Freeman.

Tighe, T. J. (1978). Concept formation and art: Further evidence on the applicability of Walk's technique. Psychonometric Science, 9, 237, 238.

Walk, R. D. (1967). Concept formation and art: Basic experiment and controls. Psychonometric Science, 9, 237, 238.

Walk, R. D., Karusaitis, K., Lebowitz, C., \& Falbo, T. (1971). Artistic style as concept formation for children and adults. Merrill-Palmer Quarterly, 17 (1), 347-356. 